\title{
EXTRAORDINARY DEATHS OF ASYLUM INPATIENTS DURING THE 1914-1918 WAR
}

by

\section{J. L. CRAMMER *}

During the 1914-1918 war there was, from year to year, a mounting number of deaths among the inpatients of some (but not all) English asylums. By the beginning of 1916 the Board of Control, the small government office responsible for offering guidance to managers and monitoring the proper running of asylums in England and Wales, was perturbed and puzzled by the figures. ${ }^{1}$ The most important function of such institutions is to keep their inmates alive. The Board recognized that the rising death rate was in some way connected with the special conditions of war-time, but could not identify what was at fault and recommend correction. Nationally, in the 97 pre-war asylums the annual death rate ran steadily at about 10 per cent to 11 per cent of the resident population. In 1915 it was already 12.1 per cent, in 191612.6 per cent, in 191717.6 per cent, in 1918 over 20 per cent ${ }^{2}$ and then fell back to its old level in 1919 and 1920. Individual asylums showed great variation, however. Some, scattered across the country, had much higher death rates than even the national average (Table 1), while others showed little or no rise from the pre-war period and these differences did not appear to be related to the size or age of the asylum, or to overcrowding. In early 1915, so that the Army could use them as military hospitals, 9 asylums were emptied of patients, who were transferred into the remaining 88 institutions, but asylum deaths really increased only afterwards, in the years up to 1918. The lack of male nurses, many of whom had enlisted, was not a convincing underlying cause either, since female and male patients, nursed only by their own sex, died in approximately equal numbers.

When the medical causes of death were examined, none of the common illnesses, such as pneumonia, dysentery or enteric fever stood out, with the exception of two: "senility" and tuberculosis. Senility was hardly a diagnosis, meaning simply old age, but tuberculosis was a national enemy, endemic in asylums and among the industrial poor, and a notable cause of death among all classes throughout the nineteenth century. In 1918 it was responsible for about a quarter of all asylum deaths. ${ }^{3}$

\footnotetext{
* J. L. Crammer, MA, MRCS, LRCP, FRCPsych, Reader Emeritus in Biological Psychiatry, Institute of Psychiatry (University of London), Maudsley Hospital, London SE5. Address for correspondence: South Grange, Fenway, Steeple Aston, Bicester, Oxon OX6 3SS.

'Board of Control, Second annual report, Part 1 for 1915, London, HMSO, 1917, p. 10. Hereinafter referred to as $B C R$, with relevant date.

${ }^{2}$ BCR 1918 , p. 20.

${ }^{3}$ Ibid., p. 18.
} 
Extraordinary deaths of asylum inpatients

Table 1: DEATHS PER THOUSAND ASYLUM PATIENTS IN 1918 (selected hospitals)

\begin{tabular}{lccc}
\hline Asylum & Total deaths & Tubercular & Influenzal \\
\hline Group A & & & \\
Northumberland & 383 & 147 & nil \\
Buckinghamshire (Aylesbury) & 346 & 96 & 30 \\
Powick (Worcester) & 325 & 162 & 9 \\
Rainhill (Lancashire) & 321 & 78 & 8 \\
\hline Group B & & & \\
Cumberland & 90 & 11 & nil \\
Canterbury & 100 & 29 & 9 \\
Severalls (Colchester) & 146 & 50 & 6 \\
Colney Hatch (N. London) & 143 & 40 & 9 \\
\hline
\end{tabular}

Average national death rate: 203 per thousand (from Board of Control, Annual report 1918, pp. 21-22). Group $A$ : 35 asylums had a higher than average death rate. The figures given are for the four worst. Group B: 45 asylums had a lower than average death rate. The figures given are for the two lowest and the two nearest the average.

As noted in the Registrar-General's Annual Reports on the nation's health, the incidence of tuberculosis had been steadily declining in the years up to 1914. During the war it began to show a small increase among civilians as a whole. Analysis of the figures for women only (to exclude distortions caused to male figures by the military call up) confirmed a rise in tubercular deaths, but showed, astonishingly, that nearly half the total increase in such deaths nationally was due to those in asylums alone. The resident asylum population numbered less than 100,000 , the national population over $32,000,000$, so the enormous contribution of asylum tuberculosis required an explanation. ${ }^{4}$

It could not be produced simply by digesting national statistics at headquarters. A probable answer could, however, have been obtained by analysing the detailed management on-site of even one high-death asylum. This was not done, but can be approached today in so far as very complete records-management minutes, visitors' report books, daily and monthly reports, Annual Reports, and many other documents-still exist in the Buckinghamshire County Record Office for the Buckinghamshire County Asylum, which, as shown in Table 1, had the second highest death rate in England and Wales. For the most part, it is necessary only to read the Annual Reports and examine closely the asylum Register of Deaths, which lists in sequence the date of death, name, sex, age, period of inpatient residence, home area, assigned medical cause of death, and post-mortem result, where available, for each patient, month after month, year after year.

This analysis helps to explain the extraordinary deaths and adds a crumb to the history of the 1914-1918 war and of English public health. But more than this, it shows popular emotion shaping medical history and raises questions of how scientific

\footnotetext{
${ }^{4}$ Registrar General, 80th Annual report of the births, deaths and marriages in England and Wales, 1917, Cd 40, London, HMSO, 1919, p. 1v. 81st Annual report, 1918, Cd, 608, London, HMSO, 1920, p. Ixvii.
} 


\section{J. L. Crammer}

knowledge can inform administrative policy, and how central and local policymakers interact.

The Buckinghamshire County Asylum opened in 1853 with 200 beds, and by 1914 after two expansions, was housing nearly 700 patients. Its general history (which quotes some of the figures of Tables 2 and 3) is available. ${ }^{5}$ The figures are derived from the Annual Reports (abbreviated to CAR) and the Register of Deaths. Table 2 demonstrates for this one asylum what the Board of Control had summed up and averaged nationally: a rising general and tubercular death rate peaking in 1918; the initiation of gross overcrowding (120 excess cases) in 1915 due to the transfer of patients from asylums taken by the Army; a fall in deaths after the war; and the transfer back to their home asylums of some of those accepted in 1915. It also shows that, whereas in 1913 and 1914 the number of patients discharged as recovered was nearly half that admitted during the year, in the war years the proportion dropped to a quarter. This could have been due to the admission of more incurable cases during wartime, but it could also have been a consequence of failure by the hospital to treat or to recognize spontaneous recovery when it had taken place. The already minimal nursing staff had been depleted by the war, and the two doctors were already overworked before the arrival of the extra 120 patients. There was bound to be some diminution in care, with such overcrowding and understaffing.

Table 3 shows that the increasing deaths affected all age groups and not simply the old and feeble or senile as had been alleged. Indeed, between 1914 and 1918 while deaths among those over 60 doubled, in the 20 to 90 age group the number quintupled. It had been further alleged that asylum mortality figures increased because more new patients already on the point of death were being admitted. Table 3 compares the number of deaths among those more than six months in hospital, with that of those who died shortly after admission (i.e. within six months). There was little change until the catastrophe of 1918.

Table 2: BUCKINGHAMSHIRE COUNTY ASYLUM: PATIENT NUMBERS AND DEATHS

\begin{tabular}{lrrrrrrrr}
\hline & 1913 & 1914 & 1915 & 1916 & 1917 & 1918 & 1919 & 1920 \\
Total number of & & & & & & & & \\
inpatients on 1 Jan. & 695 & 682 & \multicolumn{1}{c}{701} & 820 & 788 & 763 & 677 & 623 \\
Admissions during year & 171 & 189 & $264^{\mathrm{a}}$ & 151 & 170 & 260 & 249 & $301^{\mathrm{b}}$ \\
Discharged & 83 & 89 & 58 & 45 & 40 & 64 & 68 & 80 \\
Transferred & 34 & 14 & 6 & 28 & 26 & 25 & 97 & 53 \\
\hline Total deaths in year & 67 & 67 & 81 & 110 & 129 & 257 & 138 & 71 \\
Deaths from TB & 10 & 8 & 14 & 28 & 19 & $65^{\mathrm{c}}$ & 24 & 6 \\
Deaths from flu & - & - & - & - & 1 & 22 & 6 & 1 \\
\hline
\end{tabular}

Data from Asylum Visiting Committee's Annual Reports for these years.

${ }^{a}$ Includes 144 patients transferred from Northampton and Norfolk asylums.

bIncludes 130 patients from Oxford.

'Deaths were fairly evenly distributed in all four quarters of the year, whereas influenza deaths occurred in the last quarter.

5J. L. Crammer, Asylum history-Buckinghamshire county pauper lunatic asylum-St John's, London, Gaskell, 1990, p. 75. 


\section{Extraordinary deaths of asylum inpatients}

Table 3: NUMBERS OF PATIENT DEATHS BY AGE AND LENGTH OF TIME IN HOSPITAL

\begin{tabular}{|c|c|c|c|c|c|c|c|}
\hline & \multicolumn{5}{|c|}{$\begin{array}{l}\text { No. of patient deaths more than } 6 \text { months } \\
\text { after admission }\end{array}$} & & \multirow[t]{2}{*}{$\begin{array}{l}\text { No. of deaths within } \\
6 \text { months of admission }\end{array}$} \\
\hline & Age $<20$ & $20-39$ & $40-59$ & $60-79$ & $80+$ & Total & \\
\hline 1915 & 5 & 10 & 13 & 19 & 7 & 54 & 27 \\
\hline 1916 & 3 & 15 & 25 & 30 & 6 & 79 & 31 \\
\hline 1917 & 3 & 16 & 32 & 31 & 9 & 91 & 38 \\
\hline 1918 & 13 & 52 & 69 & 52 & 11 & 197 & 60 \\
\hline
\end{tabular}

Almost every Annual Report of the asylum carried details of the weekly dietary officially supplied to patients and resident staff. This had been unchanged for several years, but in late 1915 it was modified, ${ }^{6}$ principally by reducing the daily provision of bread in order to keep costs down; there was a further cut a year later. The war had caused prices to rise, but there was no official food rationing until 1918, when some price controls and subsidies were also introduced nationally. At this point the hospital dietary changed again ${ }^{7}$ to conform to the official ration allowances for the population in general (see Figure 1). A dietary is, of course, a gesture of intent, rather than what anyone actually gets to eat. This depends on what is available to the common kitchen in any week, and how it is shared between patients and staff in practice. What an individual patient gets depends also on nursing supervision. Some patients steal the food of others, some give their food away or will not eat unless coaxed. People may not have done as well as the dietary suggests, but most patients were hardly likely to do better.

Table 4 lists the weights of foods to be provided weekly in the asylum for men, both staff and patients, in 1916, and gives the approximate calorific value of each, calculated with the help of a standard book on the chemical composition of foods. ${ }^{8}$ There are difficulties about doing this. The quality of the food supplied is unknown: meat, for instance, can be all bone and fat, or lean and juicy, the same weight but with very different dietary value. For calculation here quality has been assumed to be good throughout. Some of the food was in the form of stew or meat pie, made up dishes where the proportions of ingredients, including meat could vary and there was no guarantee all portions would be alike. Nevertheless, the figures can be used comparatively, and make the point that the patients were not being well nourished.

There is a striking difference between the allowance of bread for patients and staff, and, overall, a nearly threefold difference in their daily calorie intakes, which for the patients appears to be below the accepted minimum for sedentary life. ${ }^{9}$ Much scientific work in the last quarter of the nineteenth century established about 2000 calories per day as a man's minimum requirement, with more for different activities,

\footnotetext{
${ }^{6}$ Buckinghamshire County Council, Annual report of the Visiting Committee of the Buckinghamshire county asylum for 1915, Aylesbury, 1916, p. 28. Hereinafter referred to as CAR, with relevant date.

${ }^{7}$ CAR 1918, p. 28.

${ }^{8}$ R. A. McCance and E. M. Widdowson, The chemical composition of foods, Medical Research Council special report series, No. 235, London, HMSO, 1946.

${ }^{9} \mathrm{~J}$. C. Drummond and A. Wilbraham, The Englishman's food: a history of five centuries of English diet, London, Cape, 1939, pp. 302, 432-3, 515-27.
} 


\section{J. L. Crammer}

Table 4: WEEKLY FOOD ALLOWANCE FOR MEN, 1916

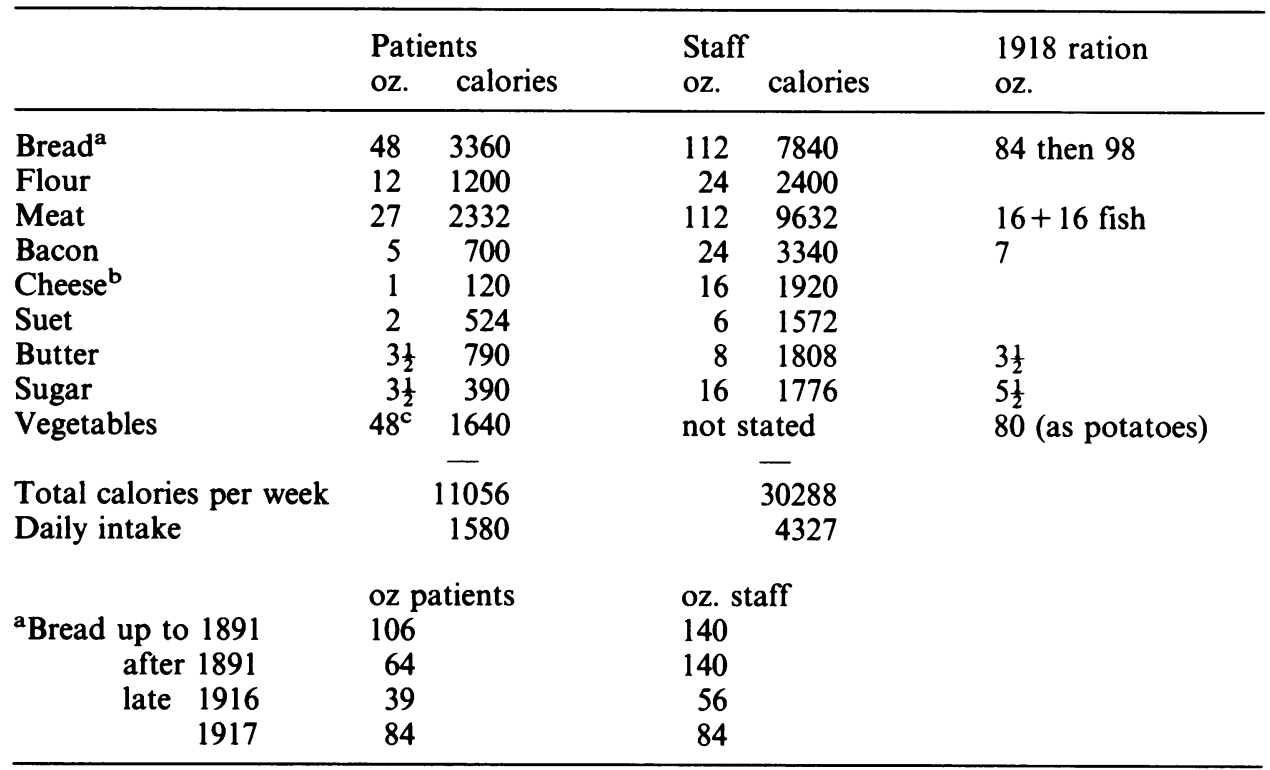

a(see CAR 1887, p. 43; 1891, p. 30, 1916, 1917 and 1918, p. 28)

bA minority of working patients got a bread and cheese snack at work at 11 a.m.

${ }^{\mathrm{c}}$ Vegetables were counted entirely as potatoes for calorie estimates only, what was actually supplied was a mixture of lesser calorific value.

Calorie values per oz.: bread $=70$, potatoes $=34$, meat $=86$, bacon $=140$.

Women got somewhat less (see CAR 1915, p. 28; 1918, p. 28).

and this was discussed clearly in standard medical works at the turn of the century, ${ }^{10}$ and repeated in non-technical form during the war. ${ }^{11}$ Bread was a major source of energy in the dietary, and its limitation could create a serious deficiency.

When, after 1916, the government began to think of the need for national food control, its first proposal was to call for a voluntary rationing of bread to $64 \mathrm{oz}$. per person per week in early 1917 . This produced very forceful protests from scientists whose proffered advice had hitherto been ignored. This voluntary diet was tried for a few months in a boys' boarding school (Christ's Hospital at Horsham) and found by the school doctor to lead to an immediate increase in ill-health and failure of growth. ${ }^{12}$ The Royal Society's confidential advice to the Ministry of Food was made public at the end of 1917 and formed the basis of the rationing introduced by stages to mid-1918. Early on it had an effect on the instructions issued by Food Controllers

${ }^{10}$ E. A. Schäfer, 'Metabolism' in E. A. Schäfer (ed.), Textbook of physiology, vol. 1, Edinburgh and London, Y. J. Pentland, 1898, pp. 868-936; R. Hutchison, 'The physiological principles of dietetics' in T. C. Allbutt and H. D. Rolleston (eds), A system of medicine, vol. 1, 2nd ed., London, Macmillan, 1905, pp. 217-20.

${ }^{11}$ Viscount Dunluce and M. Greenwood, An enquiry into the composition of dietaries with special reference to the diet of munition workers, December 1917, Medical Research Council special report, No. 13, London, HMSO, 1918. 1935.

${ }^{12}$ G. E. Friend, The schoolboy, a study of his nutrition, physical development and health, Cambridge, Heffer, 


\section{Extraordinary deaths of asylum inpatients}

and, at the end of 1917, the Buckinghamshire Asylum produced a new dietary "as revised by the Ministry of Food" 13 and noted in Table 4 (last column). It had more bread, and more potatoes assured, but was more expensive than the previous provision. Figure 1 shows how the money spent on food had failed to keep step with rising prices, but suddenly rose in 1918. It is clear that the Buckinghamshire County Council had economized on food, and carried this too far. The final economy of late 1916, reducing bread to $39 \mathrm{oz}$. per patient per week, fits in time with the death peak following in 1918. The improvement to $84 \mathrm{oz}$. weekly at the end of 1917 fits with the recovery in 1919 and 1920 . Slow starvation results in apathy and lethargy, a lowering in vitality and diminished resistance to infections. ${ }^{14}$ Tuberculosis, in particular, was known as a disease where plenty of food (as provided in sanatoria) would help recovery, and an inadequate diet predisposes sufferers to death. The rise in tubercular deaths in this asylum was consistent with food deprivation.

If underspending on food was a general factor in the deaths, the money spent on food on average per week in Group A asylums (Table 1), was less than those in Group B. Buckinghamshire at $4 s .9 \frac{1}{2} d$. in 1917 was the highest spender of the eight worst of Group A: Northumberland $3 s$. $4 \frac{1}{2} d$., Powick $2 s$. $4 \frac{1}{2} d$., Durham $3 s$. $2 d$., for instance. In Group B the five best spent $4 s .6 d$., $5 s .7 \frac{1}{2} d ., 8 s ., 2 s .11 d$., and $5 s .3 d$. respectively. ${ }^{15}$ Of course, food prices may not have been the same all over the country, and these figures take no account of any food patients may have also got from asylum farms. However, they are suggestive.

The British population at large did not appear to suffer from malnutrition during the war years, and there was even some evidence that, in spite of rising costs, its food consumption improved. ${ }^{16}$ Winter $^{17}$ has shown that men aged 46 and over (i.e. over military age) had an increased likelihood of survival in the years 1914-1917 as compared with earlier years, and that infant survival also increased across the country at this time. The civilian medical services were, however, in great disarray, ${ }^{18}$ due partly to the grasping and mismanagement of the Army, which had taken a third of the beds in workhouses and Poor Law infirmaries, and some TB sanatoria (in one case turning the children's wing into a boot store). In spite of these civilian deficiencies it is interesting that nearly half the increase in tubercular deaths came from the asylums. ${ }^{19}$ Medical officers of prisons reported that the health of prisoners showed little change through 1914-1918. Deaths nationally fluctuated but were always few, of the order of 50 to 100 in all, of which about 90 per cent occurred in those less than six months into their sentence. ${ }^{20}$

\footnotetext{
${ }^{13} \mathrm{Op}$. cit., note 7 above.

${ }^{14}$ Hutchison, op. cit., note 10 above, p. 220.

${ }^{15}$ BCR 1917, Part 2, p. 49.

${ }^{16} \mathrm{John}$ Burnett, Plenty and want: a social history of food in England from 1815 to the present day, 3rd ed., London, Routledge, 1989, pp. 249-51.

${ }_{17}$ J. M. Winter, 'Impact of the First World War on civilian health in Britain', Econ. Hist. Rev., 1977, 30 487-507.

${ }^{18}$ B. Abel-Smith, The hospitals 1800-1948: a study in social administration in England and Wales, London, Heinemann, 1964, pp. 279-81.

${ }^{19} 81$ st Annual report, op. cit., note 4 above.

${ }^{20}$ Commissioner of Prisons, Report for 1915, Cd 7837, London, HMSO, 1915, p. 100, Appendix 15, Table C; Report for 1918, Cd 9174, London, HMSO, 1918, p. 22-4.
} 


\section{J. L. Crammer}

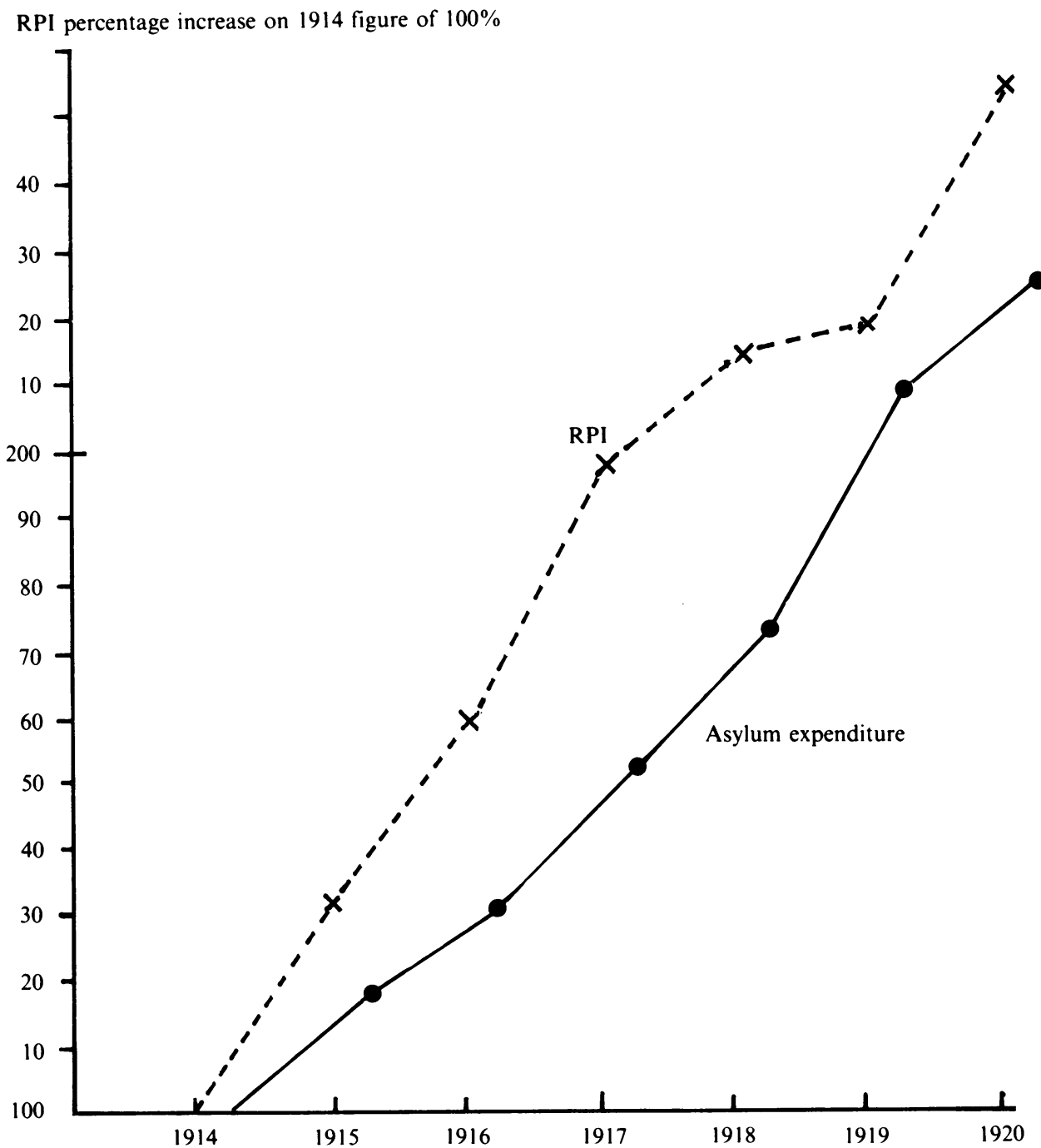

Figure 1: The average weekly cost per head of provisions at the Buckinghamshire County Asylum and the Food Retail Price Index (RPI) both expressed as percentage changes on $1914=100 \%$. The cost shown is reckoned for the year ending $31 \mathrm{March}$, the index as the value for the beginning of the calendar year to which it applies. In 1917, when RPI had risen 100\%, expenditure on food had risen only $50 \%$. Notice that the RPI rises more steeply than asylum expenditure until 1918-19, when asylum spending rises steeply and the RPI flattens with the imposition of general food rationing and subsidy, then rises with inflation in 1920. (Costs from CAR 1914, p. 43; CAR 1917, p. 24; CAR 1920, p. 24.) 


\section{Extraordinary deaths of asylum inpatients}

Why did the Board of Control fail to solve the problem of rising deaths? The evidence is that they did not try very hard. The Buckinghamshire Asylum had one of the highest death rates in the country and was little more than one hour by train from London, but no one went specifically to have a look at it, and the annual inspections in 1916 and 1918 were carried out by a lawyer. The inspector of 1919 , commenting on the deaths up to 31 December 1918, wrote that the death rate of " $34.5 \%$, an enormously high figure [was] caused largely by a very virulent epidemic of influenza which occurred in the latter months of the year", a statement quite contrary to the entries in the Register of Deaths (see Table 2) and the printed statements by the medical superintendent. ${ }^{21}$ In 1918 three members of the Board visited 26 asylums and reported that medical superintendents generally thought malnutrition was the cause of the high death toll; but they still could not understand how this could be, and speculated that perhaps the reduced diets had been introduced too abruptly, ${ }^{22}$ or that the poor quality of wartime flour was the culprit. ${ }^{23}$ The word calorie was never mentioned, nor did they seek scientific advice from outside, nor embark on any experiment to see whether changing the food (or anything else) in just one asylum would influence the death rate.

If they had consulted their colleagues of the General Board of Control for Scotland, which oversaw the fifteen royal and district asylums of that country together with about the same number of parochial and private asylums, they would have learned that the annual death rate north of the Border (9.8 per cent in 1912) had risen to only 12.1 per cent by 1917 , and 14.6 per cent in 1918 , considerably below what some English asylums were experiencing. Further, they would have learned that the Scottish Commissioners had introduced, even before 1914, the regular weighing of patients to monitor their health, and had concerned themselves to encourage an adequate dietary, daily average of 2660 calories. $^{24}$

They were not of course, scientists, though, apart from three lawyers and three other laymen, five of the Commissioners were medical doctors, and there were also three medical inspectors. According to the Medical Directory, 1914, four of the doctors had qualified between 1858 and 1880, a minimum of 34 years earlier, and four between 1891 and 1896. Three of the older medical men were ex-medical superintendents of asylums, and one younger one was still in post. One member (qualified 1871) was a consultant physician, lecturer and tutor at the Middlesex Hospital Medical School. Two of the inspectors were younger, both held the Diploma in Public Health, one was a general practitioner, the other a physician at Nottingham General Hospital. One should not perhaps expect too much from such a group, too many were elderly and possibly out of touch or asylum superintendents shaped by traditional asylum routine. There were no representatives of scientific or relevant academic disciplines. They had been appointed to see decent humane care was maintained in asylums and the laws obeyed, not to do research or solve problems.

\footnotetext{
${ }^{21}$ CAR 1918, p. 11; CAR 1919, p. 7.

${ }^{22}$ BCR 1917, p. 23.

${ }^{23}$ BCR 1918, p. 24.

${ }^{24}$ General Board of Control for Scotland, 5th Annual report, Cd 143, Edinburgh, HMSO, 1919, p. xxxi, Appendix xlviii.
} 


\section{J. L. Crammer}

What emerged from them when the war and the high deaths were over was a circular letter in January 1919 to medical superintendents and Clerks to the Visiting Committees of all county and borough asylums saying that many factors had caused the deaths and that the important thing now was to tighten up hygiene, and, in particular, to renew the attack on tuberculosis by isolating infective persons, improving diagnosis with laboratory aids such as a microscope to examine sputum, and by providing the fresh open air and good food known to promote healing. "Medical Superintendents ought not to experience any difficulty or delay in obtaining all help needed in this direction", they wrote. ${ }^{25}$ But this was entirely up to the Visiting Committees, particularly their chairmen, who had the financial power and were the employers of the superintendents. The Board of Control could advise, but had no power to insist on anything. In fact the Buckinghamshire Visiting Committee took no notice whatsoever of the Board's letter.

Before the war, when the inspectors told them they had twice as much tuberculosis in their asylum as other asylums of comparable size, they did nothing. They remained indifferent to all the educational work carried on since 1898 by the National Association for the Prevention of Tuberculosis, and to the final report of the Royal Commission on Tuberculosis, issued in 1911. They aligned themselves with the 573 (out of a total of 695) Boards of Guardians of workhouse infirmaries who in 1904 had made no attempt to separate the infective tuberculous from the other patients-but they were still so aligned in $1920 .^{26}$ They continued to do nothing, not even to sanction the purchase of a microscope. Their first post-war plan was to convert 100 beds for the use of private patients. When this project failed, they developed the hospital farm and began a series of experiments comparing fertilisers and strains of poultry. Proper treatment of asylum tuberculosis in this asylum had to wait until the coming of the National Health Service in 1949, and then, in seven years, it had vanished completely.

The attitude of the Buckinghamshire Committee to food, and their belief that, as paupers, the patients had no right to more than the barest of existences had been made clear from the outset when the Committee was set up in 1889. Their first act was to cut the expenditure on food by 20 per cent. ${ }^{27}$ The magistrates, the previous rulers, had accepted a different view, put forward by the first medical superintendent: "Of the diet, our most expensive item, I must further add that it was recommended on account of the increase in percentage of recoveries and diminution of the deaths observed to follow an improvement on that of the older asylums, the testimony of medical men engaged in treatment of the insane ... beneficial results of a liberal and nutritious dietary". ${ }^{28}$ This had remained the belief of doctors. In a standard textbook, which went through four editions between 1908 and 1921, Stoddart described the

\footnotetext{
${ }^{25}$ BCR 1918, op. cit., note 23 above, p. 26.

${ }^{26}$ Linda Bryder, Below the magic mountain: a social history of tuberculosis in twentieth-century Britain, Oxford, Clarendon Press, 1988, pp. 33, 110-12.

${ }^{27}$ Crammer, op. cit., note 5 above, pp. $110-14$; CAR 1892, pp. 4, 30.

${ }^{28}$ CAR 1853, p. 23.
} 


\section{Extraordinary deaths of asylum inpatients}

importance of plenty of good food for acute mental illness, though he did concede that for the chronic incurable demented it was permissible to practise economy. ${ }^{29}$

The dietaries of 1868 and $1888^{30}$ (under the magistrates) show a weekly bread allowance of $106 \mathrm{oz}$. That of the new management in 1892 indicates a cut to $64 \mathrm{oz}$., as well as cuts in meat and butter. Each year the Committee boasted that the weekly maintenance of its patients was always about a shilling, or 10 per cent less than the average cost in the asylums of the country as a whole. Inspectors criticized their food policy. The Commissioners in Lunacy (predecessors of the Board of Control) in their Annual Reports for 1908 and 1911 deplored "the continuance of a parsimonious tendency in connection with patients' meals which is very undesirable", and criticized asylums which cut their maintenance costs when food prices rose. Evidently the Buckinghamshire Committee was not the only management behaving in this way.

Of course the 18 county councillors - small business men, farmers, retired army and naval officers-could not be expected to know anything about calories or tuberculosis, though diets in prisons and workhouses, and the value of sanatoria, had been a matter for parliamentary debate and public enquiry for some time. ${ }^{31}$ The medical superintendent Dr Kerr, their chief executive officer, technical adviser and employee, must, however, have been aware of these matters. He had qualified with commendation from Glasgow in 1892, had worked for the higher degree of MD (1899) while an assistant in the asylum, and had subsequently published papers in the Lancet on heart diseases. ${ }^{32}$ But the Committee was not required to seek his advice or to take it if proffered. When, in late 1916, they cut the weekly bread ration to $39 \mathrm{oz}$. they did not suppose it would be lethal.

The astonishing thing is that there is no evidence of their having discussed the rising death rate, or of their trying to investigate it in any way. Committee members were required to visit the asylum eight times a year and write a note. Only once (28 August 1916) did they refer to food: "we saw the inmates at dinner, which was well served and appeared to be much enjoyed. Everything was clean and in good order". The Board of Control inspectors wrote likewise: "No complaints were made of the dietary" (November 1916), "... a few especially of the men demurred to the prevailing diet restrictions, especially the small ration of bread" (November 1917), and "one or two criticised the diet" (July 1918).

The Annual Reports of the asylum for 1914 and 1915 contain no remark by the Committee on the health of the patients during these years, but in 1916 and 1917 they wrote "the general health of the patients has on the whole been satisfactory" and in 1918 (the year in which 257 died, including 65 from TB) "the general health of the patients has been fairly satisfactory, but there has been a marked increase in the number of cases of tuberculosis, and the Institution was very seriously affected by the Influenza epidemic. Over 200 cases occurred among patients and staff, and of the former 22 ended fatally, while 4 members of staff died from this cause".

\footnotetext{
${ }^{29} \mathrm{~W}$. H. B. Stoddart, The mind and its disorders: a textbook for students and practitioners of medicine, 2nd ed., London, Lewis, 1912.

${ }^{30}$ CAR 1887 , p. 43.

${ }^{31}$ Drummond and Wilbraham, op. cit., note 9 above.

${ }^{32}$ Medical directory, 1914; Crammer, op. cit., note 5 above, p. 71.
} 


\section{J. L. Crammer}

The medical superintendent's own report was scarcely more open. In 1917 (129 deaths, 19 from TB) he said, "the health of the patients has been satisfactory, but the increase in the death rate among the older and more feeble patients and the increase of TB must be attributed in part to the altered conditions and indicate that a generous diet is necessary for the maintenance of the vitality of the insane". ${ }^{33}$ And in 1918 (257 deaths) "the general condition of the patients was fairly well maintained although the restrictions as to diet had a certain detrimental effect in the case of the more feeble and aged patients". ${ }^{34}$ That they were feeble is shown by the fact that they died; but they were not in fact the more aged (see Table 3).

This paper has drawn attention to an unprecedented number of asylum deaths nationally during the Great War in 1917 and 1918, caused by wartime conditions and estimated to have amounted to over 17,000 deaths, casualties without any war memorial. Evidence still available suggests that one important cause of these deaths was lack of enough food, reduced to save the rates. Much later, reporting on the 1939-1945 war, in which overcrowding and understaffing of asylums again took place, the Board of Control contrasted the low mortality of inpatients as compared with 1914-1918 and ascribed the difference largely to the care taken over food (daily intake estimated as 2800 calories). ${ }^{35}$ That such a lack of care could occur during the First World War shows a fundamental flaw in the organization of the English asylum system. Laymen governed a technical service (i.e. one involving specialized knowledge) without any first-hand experience or technical understanding. They could be ignorant of what work went on, or ought to have gone on in their institution, and not know when to call for specialist advice, or even be unwilling to consider doing so. They seemed unaware of how different parts interacted, that staffing, food, architecture, and medical treatment affected one another and the resulting therapeutic outcomes. The only existing corrective was the Board of Control.

Before the war, the Commissioners in Lunacy (the Board under its earlier title) had stood above all for humane care, and had tried to spread information about good practice. They had fought endlessly to avoid overcrowded wards and shortages of doctors and nurses. They, and the law, had required the keeping of numerous registers as a safeguard against malpractices. Yet, when the war came, everything was thrown to the wind in patriotic zeal. In order to empty asylums, which could then be used as military hospitals, they authorized patches of overcrowding in the remaining asylums the like of which had never been seen before. They encouraged male nurses to volunteer for military service, and out of 5,289 at the outbreak of war over half $(2,681)$ had enlisted by 1916 when conscription came in. At this point the government gave the Board the job of deciding whether the remaining staff should be reserved, and the asylums appealed to keep 2,000 men. But the Board thought that, in general, an asylum ought to manage with one-fifth of its peacetime male establishment, and granted permanent reservation to only 922 men. The case of doctors was similar, and many, including some medical superintendents, joined the Army. To reduce the work of those left behind, the Board told asylum staff to stop keeping detailed clinical

${ }^{33}$ CAR 1917, p. 11 and p. 3.

${ }^{34}$ CAR 1918, p. 11 and p. 3.

${ }^{35}$ BCR 1945, 'Dietary', p. 14. 


\section{Extraordinary deaths of asylum inpatients}

notes, and some parts of the registers, and to give up most post-mortems-all part of a structure designed to monitor patient care. ${ }^{36}$ In their zeal for the war effort they abandoned the patients whose care they were supposed to safeguard. Some blame for those 17,000 casualties must rest on their shoulders.

The NHS led to the abolition of the Board of Control in 1959, and the asylums joined the other hospitals of the country under national and regional financing. Management was taken from elected laymen and more of it passed into professional hands. But now asylums are closing and being replaced by private and public childrens' and old peoples' homes, hostels for the chronically disabled, whether mentally ill or handicapped, places where inmates stay months and years. The old problems of the asylums reappear in these new settings. How can we ensure that managers can have the best scientific knowledge of the day to help them in their decisions? How can the government monitor and regulate the medical and social services to do justice to both patients and society in general?

${ }^{36}$ BCR 1914, p. 15; BCR 1916, pp. 8-10. 